\title{
Determinants of abortion among clients coming for abortion service at felegehiwot referral hospital, northwest Ethiopia: a case control study
}

\author{
Fikreselassie Tilahun ${ }^{1}$, Abel Fekadu Dadi ${ }^{2 *}$ and Getachew Shiferaw ${ }^{3}$
}

\begin{abstract}
Background: According to the World Health Organization (WHO) estimate, one-third of pregnancies end in miscarriage, stillbirth, or induced abortion in the world. There are various reasons for a woman to seek induced abortion. However, limited information is available so far in the country and particularly in the study area. Therefore, the aim of the current study was to identify the determinants of induced abortion among clients coming for abortion care services at Bahirdar Felegehiwote referral hospital, Northwest Ethiopia.

Methods: Institutional based unmatched case-control study was conducted from September to December 2014. Interview administered questioner was used to collect primary data. Enumeration and systematic random sampling $(K=3)$ method was used to select 175 cases and 350 controls. A binary logistic regression model was fitted to identify determinant factors. Odds ratio with $95 \% \mathrm{Cl}$ was computed to assess the strength and significance of the association.

Result: All sampled cases and controls were actually interviewed. The likelihood of abortion was higher among non-married women [AOR: 18.23, 95\% Cl: 8.04, 41.32], students [AOR: 11.46, 95\% Cl: 6.29, 20.87], and women having a monthly income of less than 500 ETB [AOR: 11.46, 95\% Cl: 6.29, 20.87]. However, the likelihood of abortion was lower among women age greater than 24 years [AOR: $0.29,95 \% \mathrm{Cl}: 0.11,0.79$ ] and who had the previous history of induced abortion [AOR: $0.31,95 \% \mathrm{Cl}: 0.15,0.65]$.

Conclusion: The study identified being non-married, student, women age less than 24 years, having the previous history of induced abortion, and low monthly income as an independent determinant of induced abortion. Interventions focused on the identified determinant factors are recommended.
\end{abstract}

Keywords: Case-control study, Induced abortion, Ethiopia

\section{Background}

Every day, approximately 1000 women die from preventable causes related to pregnancy and childbirth worldwide and $99 \%$ of all maternal deaths occur in developing countries [1]. World Health Organization (WHO) estimates that, worldwide 210 million women become pregnant each year and about two-thirds of them, or approximately 130 million, deliver live infants $[1,2]$. The remaining one-third

\footnotetext{
* Correspondence: Fekten@yahoo.com

${ }^{2}$ Institute of Public Health, College of Medicine and Health Sciences,

University of Gondar, P.O.Box: 360, Gondar, Ethiopia

Full list of author information is available at the end of the article
}

of pregnancies ends in miscarriage, stillbirth, or induced abortion [3]. Of the estimated 42 million induced abortions each year, nearly 20 million are performed in unsafe conditions and results in the deaths of an estimated 47,000 women. This represents about $13 \%$ of all pregnancy-related deaths $[3,4]$.

Generally, the burden of abortion is still significant being one of the leading causes of maternal mortality and morbidity. An estimated 68,000 girls and women die of unsafe abortion and millions are injured $[5,6]$. The ratio of abortion deaths per 100,000 procedures is less than $1 / 100,000$ in developed countries while it is 
680/100,000 for Africa [7-9]. This category of abortion was even called "silent scourge" because of the high number of deaths attributable to it and its economic and social consequences [10].

The maternal mortality ratio (MMR) in Ethiopia was estimated as 420 deaths per 100,000 live births in the year 2015 [11]. According to the World Health Organization, Ethiopia had the fifth largest number of maternal deaths in 2005 and unsafe abortion is estimated to account for $32 \%$ of all maternal deaths in Ethiopia [12]. It is estimated that there are 3.27 million pregnancies in Ethiopia every year, of which approximately 500,000 ends in either spontaneous or induced abortion [13].

In 2005 Ethiopia expanded its abortion law that had previously allowed the procedure only to save the life of a woman or protect her physical health. Currently, abortion is legal in Ethiopia under certain preconditions like in cases of rape, incest or fetal impairment, if the pregnancy endangers her or her child's life, or if continuing the pregnancy or giving birth endangers her life. A woman may also terminate a pregnancy if she is unable to bring up the child, owing to her status as a minor or to a physical or mental infirmity [14].

Reasons of women to seek induced abortion are different as to the various women circumstances. A review from 27 different countries revealed that postponing, stopping childbearing and socio-economic factors such as being unable to afford a child- either in terms of a direct cost of raising a child or opportunity costs are the commonest reasons for induced abortion [15].

A study conducted in Denmark and Uganda identified being single followed by being aged 19 years or below, having two children or more, student or unemployed as the strongest determinant of women's decision to have an abortion [16, 17]. In Ethiopia, similar findings were revealed that economic problem, family size control, being single, the level of education attained by the mother, and extra-marital pregnancy were the factors that increase induced abortion [18-20].

Having this much significance of the problem, little is known about the reasons that drive women to terminate their pregnancy. Therefore, this study was conducted to identify the determinants of induced abortion. The current study was different from previous in design, and the study site, which was regional referral hospital that includes diverse population. This could support the government efforts made to prevent induced abortion and its consequence.

\section{Method}

\section{Study setting and population}

The study area was Felegehiwot referral hospital, which is found in Bahirdar city administration, Northwest of Ethiopia. Bahir Dar is found at a distance of $563 \mathrm{~km}$ away from Addis Ababa and located on the Southern shore of Lake Tana, the source of the Blue Nile. In Bahir Dar city administration, for the total of 31,800 populations, there are 2 hospitals, 10 health centers, 10 health posts, and 134 private health institutions. Felegehiwot referral hospital is one of the other referral hospitals found in the country, in which the services given for clients and the clients coming to the hospital are comparable with other similar hospitals. Researchers employed a hospital-based unmatched case-control study from September to December 2014. The source and study population consisted of pregnant women seeking maternal care services at maternal care ward. Seriously ill mothers and mothers with spontaneous abortion were excluded from the study.

Cases were selected from reproductive age women for whom safe abortion was performed or for whom post-abortion care service was provided after presenting to the hospital with an attempt of induced abortion within 1 week of presentation.

Controls were selected from antenatal care attendees in Felegehiwot referral hospital who persisted on their pregnancy after the $28^{\text {th }}$ completed gestational age.

\section{Sampling technique and sample size determination}

A systematic random sampling $(K=3)$ was used to select controls and enumeration method was used to include cases. The first interviewer in the case of control selection was based on lottery method. Researchers calculated the sample size using the Epi Info 7 STAT CALC program by taking assumptions of a $95 \%$ confidence level, $80 \%$ power and a number of children the mother had as a primary exposure variable [18]. Fifteen (15.8\%) of control women had two or more children and, $27.3 \%$ of women with induced abortion had two or more children $(\mathrm{OR}=2)$. Researchers used two controls for each case and the final sample size for the study adding $10 \%$ nonresponse rate was 175 cases and 350 controls.

\section{Data collection and quality assurance}

Pregnant women who were available during data collection period were eligible to participate in the study. Researchers used a pretested and structured Amharic questionnaire to collect information. Face-to-face interviews were conducted to collect data on independent and socio-demographic variables. Language experts translated the questionnaire from Amharic to English and back to English to ensure consistency. Researchers conducted pretest on the different area by taking $10 \%$ of the total sample size and used the revised questioner for final data collection. Two midwifery nurses collected the data after being trained. The principal investigator critically supervised the whole process of the data collection. Knowledge 
about emergency contraceptive was assessed by a single question and they were considered knowledgeable if they have answered the question as yes. However, mothers were asked to mention types of contraceptive methods and their knowledge was categorized as "mentioned at least one type" and "mentioned more than one type" based on their response.

\section{Data analysis}

All the data were checked, coded and entered using Epi Info version 7 and analyzed using STATA Version 12. Researchers checked the extent of outliers, the different statistical assumptions, and applied the appropriate correction mechanisms prior to analysis. Association of each independent variable was assessed with binary logistic regression. Variables showing statistically significant associations with the outcome variables (up to $p=0.2$ ) were considered as potential confounders of abortion and simultaneously subjected to stepwise multiple logistic regression models to determine the significant independent risk factor of abortion. Adjusted odds ratio with a $p$-value $<0.05$ was used to report the significant factors.

Table 1 Socio- demographic characteristics of mothers came to Felege Hiywot Referral Hospital, Amhara Region, North West Ethiopia

\begin{tabular}{|c|c|c|}
\hline \multirow[t]{2}{*}{ Study variables } & \multicolumn{2}{|c|}{ Abortion status } \\
\hline & Case, N (\%) & Control, N (\%) \\
\hline \multicolumn{3}{|l|}{ Residence } \\
\hline Urban & $78(44.6)$ & $235(67.1)$ \\
\hline Rural & $97(55.4)$ & $115(32.9)$ \\
\hline \multicolumn{3}{|l|}{ Age of the mother } \\
\hline$<24$ years & $132(75.4)$ & $131(37.4)$ \\
\hline$>=24$ years & $43(24.6)$ & $219(62.6)$ \\
\hline \multicolumn{3}{|l|}{ Religion } \\
\hline Orthodox & $150(85.7)$ & $305(87.1)$ \\
\hline Other religion followers & $25(14.3)$ & $45(12.9)$ \\
\hline \multicolumn{3}{|c|}{ Educational status of the mother } \\
\hline Below secondary school & $64(36.5)$ & $136(38.8)$ \\
\hline Secondary and above & $111(63.5)$ & $214(61.2)$ \\
\hline \multicolumn{3}{|l|}{ Occupation } \\
\hline Student & $84(48)$ & $11(3.1)$ \\
\hline Non-student & $91(52)$ & $339(96.9)$ \\
\hline \multicolumn{3}{|l|}{ Marital status } \\
\hline Single & $103(58.8)$ & $31(8.9)$ \\
\hline Married & $72(41.2)$ & $319(91.1)$ \\
\hline \multicolumn{3}{|l|}{ Income } \\
\hline$<=500$ ETB & $105(60.0)$ & $48(13.7)$ \\
\hline$>500$ ETB & $70(40.0)$ & $302(86.3)$ \\
\hline
\end{tabular}

\section{Result}

Socio-demographic characteristics of the mothers

All case and control women expected were interviewed. Among interviewed women, 78 (44.6\%) of cases and 235 (67.1\%) of controls were urban residents. One hundred thirty-two $(75.4 \%)$ of the cases and $131(37.4 \%)$ of the controls were less than 24 years and about 150 (85.7\%) of cases and $305(87.1 \%)$ of controls were Orthodox Christianity followers. Regarding the educational status of the women, $64(36.5 \%)$ of the cases and $136(38.8 \%)$ of the controls were below secondary school while the rest were a secondary and above level of education (Table 1).

\section{Maternal characteristics of the women}

Concerning family planning usage of the women, 55 (31.4\%) of cases and 77 (22\%) of controls had not ever used any method of family planning. Ninety-six (54.8\%) of cases and 143 (40.8\%) of controls had knowledge about emergency contraceptive method while $50(28.6 \%)$ of cases and $67(19.1 \%)$ of controls had ever used an emergency contraceptive (Table 2).

Table 2 Maternal characteristics of mothers came to Felege Hiywot Referral Hospital, Amhara Region, North West Ethiopia

\begin{tabular}{lll}
\hline Study variables & \multicolumn{2}{l}{ Abortion status } \\
\cline { 2 - 3 } & Case, N (\%) & Control, N (\%) \\
\hline Family planning method used & $55(31.4)$ & $77(22.0)$ \\
Ever used no method & $120(68.6)$ & $273(88.0)$ \\
Ever used at least one method & & \\
Emergency contraceptive knowledge & $96(54.8)$ & $143(40.8)$ \\
Yes & $79(45.2)$ & $207(59.2)$ \\
No & & \\
Emergency contraceptive method used & $50(28.6)$ & $67(19.1)$ \\
Yes & $125(71.4)$ & $283(80.9)$ \\
No & & $185(52.8)$ \\
Number of live children the mother had & $122(69.7)$ & $165(47.2)$ \\
Had no children & $53(30.3)$ & \\
Had at least one children & & $217(61.2)$ \\
Previous abortion history & $15(8.6)$ & $57(16.3)$ \\
Yes & $160(91.4)$ & $293(83.7)$ \\
No & & \\
Contraceptive method knowledge & $122(69.7)$ & $348(99.4)$ \\
Mention at least one method & $53(31.3)$ & $2(0.6)$ \\
Mention no method & & \\
Gravidity & & \\
One pregnancy and above pregnancy & & \\
\hline
\end{tabular}




\section{Reason for requesting abortion}

The reason for requesting abortion was collected from cases of the current study. Accordingly, from 175 cases, the majority 63 (36\%) mentioned that the reason for their request was fear of school dropout. The other reasons that frequently mentioned by the cases were maternal related problems followed by unwanted pregnancy.

\section{Determinants of Mothers' abortion}

After adjusting for other confounding variables: age and occupation of the mothers, marital status, monthly income, and mother's previous abortion history were the variables that retained in the final model.

Likewise, the odd of abortion among mothers of age 24 and above years was 0.31 [95\% CI: 0.15, 0.65]. Similarly, the odd of abortion among the students was 7.4 [95\% CI: 2.93, 18.69] times higher as compared to their counterparts. Marital status of the mothers was also the other variable that was significantly associated with mother's choice to undertake abortion. Likewise, non-married (single) were 18.23 [95\% CI: 8.04, 41.32] times more likely to abort as compared to married mothers. Similarly, the odds of abortion was 11.46 [95\% CI: 6.29, 20.87] times higher among mothers of monthly income less than or equal to five hundred Ethiopian birr.

Among factors related to maternal characteristics, mothers' previous abortion history was the only factor that significantly affected mother's decision to commit abortion. Correspondingly, the odds of committing current abortion was 0.29 [95\% CI: 0.11, 0.79] times lesser among mothers who reported previously history of abortion (Table 3).

\section{Discussion}

The current case-control study was conducted to identify factors that determine mothers' abortion request. Accordingly, age, occupation, marital condition, and income of the mothers were identified as socio-demographic determinant factors while previous abortion history was the only factor that was related to maternal characteristics.

Age of the cases as a factor for requesting abortion is repeatedly reported in different studies conducted so far $[16,17]$. Similarly, in this study, $75.4 \%$ of cases requesting abortion are those aged less than 24 years. This might be due to the fact that most of the time females in this age category were in schools or they were not economically and socially able to lead their life.

The alarming finding of this study was that, majority of the cases were students and they were seven times higher to commit abortion compared to their controls. This was revealed by different studies conducted so far in which considerably high percent of cases were students [15, 21-23]. Moreover, from the descriptive data obtained,
$36 \%$ of the respondents mentioned that their reason to request abortion was fear of school dropout.

The other socio-demographic variable which had an effect on mothers' decision to request an abortion was marital status. The study revealed that being non-married (single) puts the cases on eighteen times higher risk of requesting abortion compared to the married ones. This finding was also supported by studies published elsewhere $[18,19]$. This could also be because of economic and social factors related to the mother and psychological impact related to the newborn while growing in the environment of missing fathers. Moreover, mothers could fear to bring up their newborn independently in such environment.

The other important factor that was associated with higher proportion of cases was their lower economic background. The odds of requesting abortion was eleven times higher among cases who reported that their monthly income was less than five hundred Ethiopian birr. This finding was comparable with a review from 27 different countries and similar studies conducted in Ethiopia $[15,20]$. The possible explanation might be women with the lower economic condition might face a challenge to care and grow their child. Besides, $2.3 \%$ of the mothers mentioned that the reason for requesting the current abortion was the presence of too many children in the household and this might pose an additional challenge to the family.

From maternal characteristics, previous abortion history was the only factor that had a significant association with mothers' tendency to request the current abortion. Likewise, the odd of requesting the current abortion was $71 \%$ lesser among women having previous abortion history compared to their foil and it is in agreement with previously published articles $[24,25]$. This might be the result of a positive lesson learned from the previous abortion. Furthermore, $2.3 \%$ of the mothers mentioned that fear of the previous complication made them abort the current pregnancy.

The study employed relatively sufficient sample size that could enhance the representativeness of the population. Incident cases were used to minimize the problem of establishing a temporal relationship and as the study was conducted at regional referral hospital with an experienced gynecologist, the issue of misclassification between spontaneous and induced abortion could be resolved. However, since the study was an institutional based casecontrol study, other limitations of such study might not be avoided and the study finding is also prone for social desirability bias.

\section{Conclusion}

A considerable proportion of abortion was significantly higher among cases with age less than 24 years, students, unmarried, had no previous abortion history, and lower 
Table 3 Factors associated with requesting abortion of mothers came to Felege Hiywot Referral Hospital, Amhara Region, North West Ethiopia

\begin{tabular}{|c|c|c|c|c|}
\hline \multirow[t]{2}{*}{ Study variables } & \multicolumn{2}{|c|}{ Abortion status } & \multirow[b]{2}{*}{ COR $(95 \% \mathrm{Cl})$} & \multirow[b]{2}{*}{ AOR $(95 \% \mathrm{Cl})$} \\
\hline & Case, $N(\%)$ & Control, N (\%) & & \\
\hline \multicolumn{5}{|l|}{ Age of the mother } \\
\hline$<24$ years & $132(75.4)$ & $131(37.4)$ & 1 & 1 \\
\hline$>=24$ years & $43(24.6)$ & 219 (62.6) & $0.19(0.13,0.29)$ & $0.31(0.15,0.65)^{*}$ \\
\hline \multicolumn{5}{|l|}{ Occupation } \\
\hline Student & $84(48)$ & $11(3.1)$ & $28.44(14.56,55.57)^{*}$ & $7.40(2.93,18.69)^{*}$ \\
\hline Non student & $91(52)$ & 339 (96.9) & 1 & 1 \\
\hline \multicolumn{5}{|l|}{ Marital status } \\
\hline Single & $103(58.8)$ & $31(8.9)$ & $14.72(9.14,23.69)^{*}$ & $18.23(8.04,41.32)^{*}$ \\
\hline Married & $72(41.2)$ & $319(91.1)$ & 1 & 1 \\
\hline \multicolumn{5}{|l|}{ Income } \\
\hline$<=500$ ETB & $105(60.0)$ & $48(13.7)$ & $9.43(6.14,14.49)^{*}$ & $11.46(6.29,20.87)^{*}$ \\
\hline$>500 \mathrm{ETB}$ & $70(40.0)$ & $302(86.3)$ & 1 & 1 \\
\hline \multicolumn{5}{|l|}{ Family planning method used } \\
\hline Ever used no method & $55(31.4)$ & $77(22.0)$ & $1.62(1.08,2.44)^{*}$ & \\
\hline Ever used at least one method & $120(68.6)$ & $273(88.0)$ & 1 & \\
\hline \multicolumn{5}{|l|}{ Emergency contraceptive knowledge } \\
\hline Yes & $96(54.8)$ & $143(40.8)$ & $1.76(1.22,2.54)^{*}$ & \\
\hline No & $79(45.2)$ & $207(59.2)$ & 1 & \\
\hline \multicolumn{5}{|l|}{ Ever used Emergency contraceptive } \\
\hline Yes & $50(28.6)$ & $67(19.1)$ & $1.69(1.11,2.58)^{*}$ & \\
\hline No & $125(71.4)$ & $283(80.9)$ & 1 & \\
\hline \multicolumn{5}{|c|}{ Number of live children the mother had } \\
\hline No children & $122(69.7)$ & $185(52.8)$ & 1 & \\
\hline One child and above & $53(30.3)$ & $165(47.2)$ & $0.49(0.33,0.72)$ & \\
\hline \multicolumn{5}{|l|}{ Previous abortion history } \\
\hline Yes & $15(8.6)$ & $57(16.3)$ & $0.48(0.26,0.88)$ & $0.29(0.11,0.79)^{*}$ \\
\hline No & $160(91.4)$ & $293(83.7)$ & 1 & 1 \\
\hline \multicolumn{5}{|l|}{ Gravidity } \\
\hline One pregnancy & $122(69.7)$ & $133(38.8)$ & 1 & \\
\hline Two and above pregnancy & $53(31.3)$ & $217(61.2)$ & $3.75(2.54,5.53)^{*}$ & \\
\hline
\end{tabular}

*significant at $P$-value $<0.05$

monthly income of 500 Ethiopian birr. Therefore, Bahirdar health office and regional health bureau shall take intervention targeting the identified factors could probably reduce the burden of induced abortion and its consequences in this population.

\section{Acknowledgement}

We would like to acknowledge Amhara regional health bureau and felegehiwot referral hospital who endorsed us to undertake this study. Authors gratefully thanks study participants and data collectors' who actively participated in this research work.

\section{Funding}

This research received no specific grant from any funding agency in the public commercial, or not for profit sectors.

\section{Availability of data and materials}

All the required data has been included in the manuscript.

\section{Authors' contributions}

FT was involved in the design, implementation of the study, datacollection, statistical analysis, and drafted the manuscript. AF was involved in the design, performed statistical analysis, contributed to draft and critically review the scientific content of the manuscript. GS was involved in the design, implementation of the study, data collection and drafing of the manuscript. All authors read and approved the final manuscript.

\section{Authors' information}

$\mathrm{FT}$ is working in Debrebrhan Hospital. AF is working as instructor of Epidemiology in Institute of Public Health, College of Medicine and Health Sciences, University of Gondar, Gondar, Ethiopia. GS is working in Gynecology department in College of Medicine and Health Sciences, University of Gondar Hospital, Gondar, Ethiopia. 


\section{Competing interests}

The authors declare that they have no competing interest.

\section{Consent for publication}

Consent for publication is secured from study participants.

\section{Ethics approval and consent to participate}

Ethical approval was obtained from the Ethical clearance committee of the School of Medicine, College of Medicine and Health Sciences, University of Gondar prior to the commencement of the study. Confidentiality of the participants' information was maintained by giving participant code number and locking the data in the cupboard and password computer. The interviewer was not continued unless the respondents respond as "YES" and put their signature to participate. Counseling about post-abortion care including contraceptive service was provided to aborted women.

\section{Author details}

${ }^{1}$ Debrebrhan Hospital, Debre Berhan, Ethiopia. ${ }^{2}$ Institute of Public Health, College of Medicine and Health Sciences, University of Gondar, P.O.Box: 360, Gondar, Ethiopia. ${ }^{3}$ College of Medicine and Health Sciences, University of Gondar Hospital, Gondar, Ethiopia.

\section{Received: 23 October 2016 Accepted: 18 January 2017}

\section{Published online: 14 February 2017}

\section{References}

1. World Health Organization (WHO). Unsafe Abortion: Global and Regional Estimates of the Incidence of Unsafe Abortion and Associated Mortality in 2008. 6th ed. WHO: Geneva; 2011.

2. World Health Organization (WHO): Maternal mortality: fact sheet $N^{\circ} 348$. Accessed from [http://www.who.int/mediacentre/factsheets/fs348/en/index. html] Accessed on 20 Dec 2014

3. World Health Organization (WHO), Unsafe abortion: Global and Regional Estimates of the Incidence of Unsafe Abortion and Associated Mortality in 2011, 5th ed.

4. WHO, Understanding abortion: new studies ask why women resort to abortion. 2006, progress; 25:1

5. WHO. Unsafe Abortion, Global and Regional Estimates of Incidence of Mortality Due to Unsafe Abortion with a Listing of Available Country Data. Geneva: World Health Organization; 2011.

6. Population Reference Bureau (PRB), Abortion facts and figures. 2011 accessed from http://www.prb.org. Accessed on 21 Oct 2014.

7. The Alan Guttmacher Institute (1999) Sharing responsibility: women, society, and abortion worldwide. New York. Available: http://www.guttmacher.org/ pubs/sharing.pdf Accessed 26 Dec 2014. 26 p.

8. Shah I, Ahman E. Unsafe abortion in 2008: global and regional levels and trends. Reprod Health Matters. 2010;18:35.

9. Family planning: a key component of post abortion care Consensus Statement: International Federation of Gynecology and Obstetrics (FIGO), International Confederation of Midwives (ICM), International Council of Nurses (ICN), and (USAID),2009.

10. Grimes DA. Unsafe abortion: the silent scourge. Br Med Bull. 2003;67:99-113.

11. WHO, UNICEF, UNFPA and The World Bank estimates. Trends in maternal mortality: 1990 to 2013

12. Central Statistical Authority [Ethiopia]: Ethiopia Demographic and Health Survey, 2005. Addis Ababa, Ethiopia

13. Facts on unintended pregnancy and abortion in Ethiopia, IPAS, Guttmacher institute, New York, NY, USA, 2010.

14. The federal Democratic Republic of Ethiopia, Ministry of Health, Family Health Department: Technical and procedural guidelines for safe abortion services in Ethiopia. Addis Ababa; 2006.

15. WHO, Global and Regional Estimates of the incidence of unsafe abortion and associated mortality in 2000, 2004, 4th edition.

16. Rasch V, Gammeltoft T, Knudsen L, Tobiassen C, Ginzel A, Kempf L. Induced abortion in Denmark: effect of socioeconomic situation country of birth Eur J Public Health. 2008:18(6):144-9.

17. Dank K. Domestic violence as a risk factor or unwanted pregnancy and induced abortion in Mulago Hospital, Kampala, Uganda. Trop Med Int Health. 2006;2(1):90-101.

18. Fantahun M, Worku S: Unintended pregnancy and induced abortion in a town with accessible family planning services. Ethiopia J Health-dev. 2006;20 (2).
19. Mahlet T, Morankar S: Knowledge attitude and practice of induced abortion and its outcome among regular female students in Jimma University, Ethiopia, Master's Thesis. Jimma University, School of Public Health; 2008.

20. Tesfaye G, Zambia MT, Semahegn A. Induced abortion and associated factors in health facilities of Guraghe zone, southern Ethiopia. J Pregnancy. 2014;2014:295732

21. Animaw W, Bogale B. Abortion in university and college female students of Arba Minch town, Ethiopia, 2011. Sex Reprod Healthc Off J Swed Assoc Midwives. 2014;5(1):17-22

22. Gelaye AA, Taye KN, Mekonen T. Magnitude and risk factors of abortion among regular female students in Wolaita Sodo University, Ethiopia. BMC Womens Health. 2014;14:50.

23. Lema VM, Rogo KO, Kamau RK. Induced abortion in Kenya: its determinants and associated factors. East Afr Med J. 1996;73(3):164-8.

24. Taylor D, Postlethwaite D, Desai S, James EA, Calhoun AW, Sheehan K, Weitz TA. Multiple determinants of the abortion care experience: from the patient's perspective. Am J Med Qual Off J Am Coll Med Qual. 2013;28(6):510-8.

25. Amatya A. Factors for abortion-seeking among women attending health facilities. J Nepal Health Res Counc. 2011:9(1):25-9.

\section{Submit your next manuscript to BioMed Central and we will help you at every step:}

- We accept pre-submission inquiries

- Our selector tool helps you to find the most relevant journal

- We provide round the clock customer support

- Convenient online submission

- Thorough peer review

- Inclusion in PubMed and all major indexing services

- Maximum visibility for your research

Submit your manuscript at www.biomedcentral.com/submit
Biomed Central 